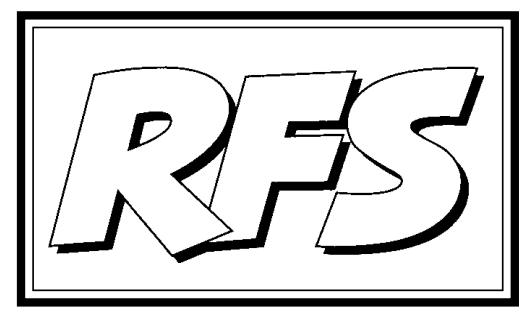

Revista de Fomento Social, 58 (2003), 535-538

\title{
Mesa redonda de la Organización Internacional del Café en Londres
}

La mesa redonda "International Coffee Crisis-Looking for Long-Term Solutions", organizada conjuntamente por la Organización Internacional del Café (OIC) y el Banco Mundial, tuvo lugar el pasado 19 de mayo en la sede central de la OIC en Londres. Participaron unos 250 delegados representando a países productores y consumidores, el sector privado, ONG, instituciones multilaterales y la prensa.

La intención principal de este evento era reunir a decisores de alto nivel de los diferentes sectores implicados en esta situación para buscar soluciones concretas que permitan redirigir la crisis hacia el desarrollo sostenible.

La mesa redonda comenzó a las 9'30 de la mañana y terminó a las 18'30, y

1 Fundación ETEA por el Desarrollo y la Cooperación. Observador invitado a la mesa redonda. 
estuvo dividida en dos sesiones. La primera, con el tema "Café y commodities en el comercio internacional: un área problemática", contó con las aportaciones de:

- Néstor Osorio, Director Ejecutivo de la OIC.

- Kevin Cleaver, Director de Agricultura y Desarrollo Rural del Banco Mundial.

- Saint-Cyr Djikalou, Representante permanente de la OAMCAF (Organización Africana y de Madagascar del Café).

- Linneu Carlos da Costa Lima, Secretario para Producción y Comercio del Ministerio de Agricultura de Brasil.

- Bernard Petit, Director General para Desarrollo de la Comisión Europea.

- J uan Manuel Santos, anterior Ministro de Finanzas y Comercio Exterior de Colombia.

- Glenys Kinnock, Parlamento Europeo.

La sesión de la tarde estuvo dedicada a "Buscando soluciones - diversificación, calidad, valor añadido y desarrollo del mercado". Los panelistas fueron:

- Phil Bloomer, Head of Advocacy de Oxfam Gran Bretaña.

- Simon Kester, Chairman de la Corporación Europea del Café.

- Michael R. Neumann, de Neumann Gruppe GMBH.

- Gabriel Silva Luján, General Manager de FEDERACAFÉ.

- Olle Tegstam, Senior Vice-President de Nestec Ltd.

- Bruce Tozer, de Rabobank International.

- Anemieke Wijn, de Kraft Foods Inc.

Las aportaciones de los panelistas, así como las resultantes de los debates posteriores, fueron realmente interesantes. Como había poco tiempo para cada intervención, las ideas se expresaban de manera clara y directa ("franca", en palabras de Kevin Cleaver). Resumo a continuación algunas de estas aportaciones.

Había dos posturas claramente contrapuestas en cuanto a la búsqueda de soluciones: 
- Quienes apostaban por soluciones "de mercado" (fundamentalmente, mejora de la calidad de la producción y los procesos, promoción del consumo de café en mercados emergentes...), rechazando formas "agresivas" de intervención. Aquí se alineaban las grandes multinacionales y, en buena medida, el Banco Mundial.

- Quienes no rechazaban intervenciones más decididas en el mercado, desde la vuelta al sistema de cuotas por país a la retirada del mercado (literalmente, la "quema") del excedente de peor calidad (calculado en torno a un $7 \%$ de la producción total). En esta postura, aunque con propuestas no coincidentes, estaban buena parte de los países productores (Colombia, Centroamérica, varios países africanos...) y Oxfam². Incluso dio la impresión de que el Director Ejecutivo de la OIC no terminaba de descartar retomar algún sistema similar al antiguo de las cuotas de producción, roto tras la salida de EEUU de la OIC, de la cual ésta parece que salió muy debilitada. Por cierto, que hubo varias llamadas al retorno estadounidense a esta institución.

- A la hora de buscar causas, había un cierto consenso en admitir que el sistema puro de mercado no había funcionado. Algunas intervenciones no profundizaban más, y limitaban el origen de la crisis al exceso de oferta (lo que serviría para justificar la retirada de estos excedentes). Otras culpaban al antiguo sistema de cuotas, que había reducido la eficiencia y la capacidad de innovación del sector entre los miembros, haciénd olos muy vulnerables a la libre competencia. No hubo alusiones directas culpando al fuerte crecimiento de las producciones vietnamita $y$, en menor medida, brasileña (ambos países son miembros de la OIC). De hecho, fue muy alabada la política productiva y de promoción del consumo interno de Brasil.

- Al hablar de diversificación, llamó la atención que se limitara ésta a la relacionada con cultivos alternativos. Hubo poquísimas alusiones a la diversificación de actividades. En este punto, se criticó abiertamente la postura de Japón, EEUU y especialmente la Unión Europea, porque la diversificación de cultivos estaba fuertemente limitada por las restricciones a introducir productos agrarios en estos países.

2 Véase a continuación el documento de Oxfam Internacional titulado "Europa y la Crisis del Café". 
- En relación con esto, y como pura apreciación personal, la postura de la Unión Europea es muy débil en estos foros. Los representantes de los países miembros no intervienen porque no quieren que su postura se interprete como una opinión comunitaria, pero tampoco existe una postura común sobre el tema. Este "círculo vicioso" impide en la práctica a la UE defender sus posiciones (si éstas existen como tales) claramente. Es posible que también rigiera un cierto criterio de prudencia ante las entonces inminentes conversaciones agrícolas en el seno de la OMC.

- El fortalecimiento institucional es otro aspecto que fue muy poco contemplado. Como mucho, se insistió en la importancia de reforzar las asociaciones de productores, exportadores..., pero no hubo referencias a la necesidad de fortalecer a las instituciones de los países productores.

- Tampoco hubo alusiones a la ayuda de emergencia. Podría parecer justificable este "olvido", toda vez que el objetivo de la mesa redonda estaba orientado hacia las soluciones a largo plazo. Sin embargo, los problemas alimentarios consecuencia de esta crisis empiezan a tomar carácter estructural en algunos países, por lo que resulta muy significativo que no se quisiera adoptar medidas estratégicas de seguridad alimentaria.

- Por último, llamó la atención que se reclamase la importancia de la cooperación internacional en estos procesos ( por ejemplo, el titular del Financial Times del día siguiente era "Co-operation needed to stop coffee crisis"), y que, sin embargo, su presencia fuese tan reducida (Banco Mundial, obviamente, y algún organismo de Naciones Unidas).

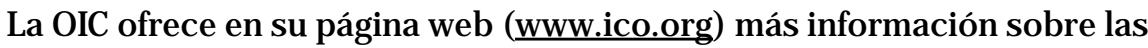
discusiones y resultados de la mesa redonda. En definitiva, y como decía al principio, la reunión fue intensa y productiva en cuanto a opiniones, aclaración de posturas e incluso con algún resultado concreto (como el compromiso de al gunas multinacionales y ONG de crear una mesa de diálogo sobre esta crisis). 